\title{
STUDI SEBARAN AIR LINDI BERDASARKAN KORELASI DATA RESISTIVITAS 2D, DATA UJI LABORATORIUM DAN DATA PEMBORAN TPA NGIPIK KABUPATEN GRESIK
}

\author{
Ahmad Qomaruddin Arsyadi ${ }^{1}$, Dwa Desa Warnana ${ }^{1}$, Nila Sutra ${ }^{2}$, Ria Asih Aryani Soemitro ${ }^{2}$ \\ ${ }^{1}$ Teknik Geofisika, Fakultas Teknik Sipil, Lingkungan dan Kebumian, Institut Teknologi Sepuluh Nopember Surabaya, \\ ${ }^{2}$ Teknik Sipil, Fakultas Teknik Sipil, Lingkungan dan Kebumian, Institut Teknologi Sepuluh Nopember Surabaya \\ e-mail : ahmad13@mhs.geofisika.its.ac.id
}

\begin{abstract}
Abstrak. TPA Ngipik Kabupaten Gresik dalam perencanaannya dibuat dengan menerapkan sistem Sanitary Landfill. Namun saat ini TPA Ngipik telah beroperasi dengan sistem pengelolaan Open Dumping sejak tahun 2003. Penerapan sistem Open Dumping menyebabkan pencemaran mudah terjadi baik pencemaran air, tanah dan udara. Penelitian ini mengorelasikan data resistivitas 2D, uji resistivitas skala laboratorium dan data hasil pemboran. Penelitian ini ditujukan untuk mengidentifikasi sebaran lindi dan kedalamannya berdasarkan korelasi data tersebut. Telah dilakukan pengukuran Resistivitas 2D Konfigurasi Wenner-Schlumberger dengan spasi $0.5 \mathrm{~m}$ dan total panjang $15.5 \mathrm{~m}$ pada musim kemarau dan musim penghujan. Dilakukan pula pengujian resistivitas skala laboratorium sebagai data korelasi Resistivitas 2D. Hasil penelitian menunjukkan bahwa hasil inversi pengukuran sesuai dengan litologi lempung dengan rentang resistivitas sebesar $0.1-43.78 \Omega \mathrm{m}$ dan telah sesuai dengan data hasil pemboran berupa litologi lempung hingga kedalaman $30 \mathrm{~m}$. Pada lintasan pengukuran juga telah teridentifikasi terdapat sebaran air lindi dengan nilai resistivitas sebesar $0.1-1.5 \Omega \mathrm{m}$. Kedalaman sebaran air lindi dari hasil penelitian ialah lebih besar dari 1 meter.
\end{abstract}

Kata Kunci : TPA Ngipik, sebaran, air lindi, resistivitas

Abstract. Ngipik Landfill at Gresik Regency in the planning will be made with applied sanitary landfill system. But, since 2003 Ngipik Landfill have been operated with Open Dumping System. Applied of Open Dumping System cause a pollution occurred easily, both pollution of water, soil and air. This research correlate 2D Resistivity Data, laboratory scale resistivity test and boring data. The purpose of this research is to identify a leachate migration based on correlation of primer and secondary data. Geoelectrical measurement with wenner-schlumberger array have been done with 0.5 meters space of electrode and 15.5 meters length of line during dry season and wet season. Laboratory scale resistivity test have also been performed as correlation data to $2 D$ Resistivity. The results showed that resistivity inversion appropriate with clay that resistivity value is $0.1-43.78 \Omega \mathrm{m}$ and appropriate with boring data that show clay lithology until 30 meters depth. At measurement line have been identified a leachate migration with resistivity value $0.1-1.5 \Omega \mathrm{m}$. The depth of leachate migration from this research is more than 1 meters.

Keywords : Ngipik Landfill, Migration, Leachate, Resistivity

\section{PENDAHULUAN}

TPA Ngipik merupakan salah satu TPA skala besar yang beroperasi di Kabupaten Gresik. Dalam perencanaannya, TPA Ngipik akan dibangun dengan sistem pengelolaan Sanitary Landfill. Namun saat ini TPA Ngipik telah beroperasi sejak tahun 2003 dengan sistem pengelolaan Open Dumping (BAPPEDA Kabupaten Gresik, 2016). Sanitary Landfill merupakan sistem pengelolaan sampah yang menggunakan lapisan penahan resapan air lindi serta adanya saluran air lindi beserta persyaratan tertentu. Sedangkan sistem Open Dumping yakni sistem pengelolaan sampah tanpa adanya aturan tertentu, langsung dibuang dan ditumpuk pada area yang sudah ditentukan (Widyatmoko \& Moerdjoko, 2002).

Akibat dari penerapan sistem Open Dumping maka akan terjadi penyebaran air lindi secara cepat dan luas. Hal ini dikarenakan tidak adanya lapisan penahan di bawah permukaan tumpukan sampah. Kondisi ini bisa menyebabkan terjadinya pencemaran air tanah akibat dari rembesan air lindi tersebut. Hal itu yang menjadi dasar penelitian ini dilakukan agar dapat diketahui sebaran air lindi dan kedalaman sebarannya. Dilakukan pula pengukuran 
pada dua musim berbeda untuk mengetahui perbedaan sebarannya.

Dalam penelitian ini dilakukan beberapa metode pengujian diantaranya pengukuran Resistivitas 2D konfigurasi Wenner-Schlumberger, uji resistivitas skala laboratorium dan didukung dengan data hasil pemboran. Digunakan metode Resistivitas 2D konfigurasi Wenner-Schlumberger karena metode ini sudah terbukti dapat mendeteksi sebaran air lindi seperti yang dilakukan oleh Putra (2012) di TPA Temesi Bali, Lopes et.al (2012) di Sardas Landfill dan Parlainggonan (2011) di TPA Kelurahan Sumur Batu Bekasi.

\section{TINJAUAN PUSTAKA}

\section{Geologi Regional}

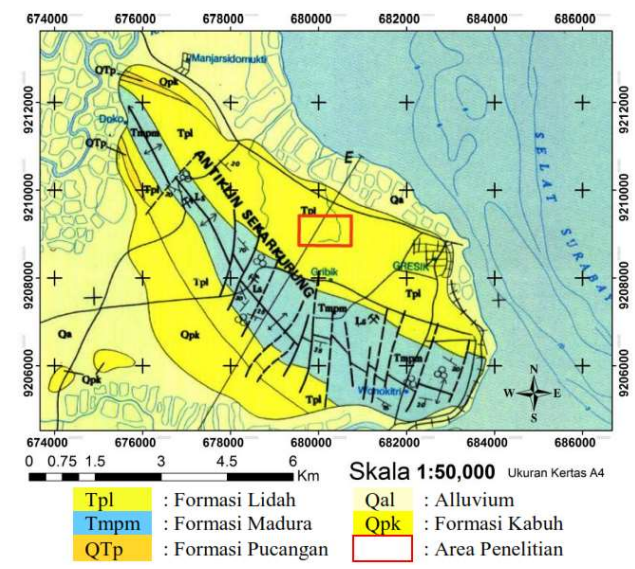

Gambar 1. Geologi Regional Penelitian (Sukardi, 1992)

Wilayah Kabupaten Gresik masuk ke dalam peta geologi lembar Surabaya-Sapulu di mana pada wilayah Gresik terdapat struktur antiklin Sekarkurung. Pada Gambar 1 terlihat banyak struktur patahan (struktur garis hitam putus-putus) yang ada di sepanjang antiklin Sekarkurung yang memiliki arah Tenggara-Barat Laut. Formasi dari muda ke tua ialah Alluvium dengan umur Quarter, Formasi Kabuh dengan umur Quarter, Formasi Pucangan dengan umur Quarter, Formasi Lidah dengan umur Tersier dan Formasi Madura dengan umur Tersier. Area penelitian yang ditunjukkan dengan kotak berwarna merah berada pada Formasi Lidah dengan susunan batulempung biru, batulempung kehitaman, pejal dan keras bila kering, sedikit kandungan fosil serta batulempung pasiran. Formasi Lidah memiliki karakteristik kandungan lempung yang tebal (Sukardi, 1992). Pada Gambar 1 tepat di area penelitian terdapat garis hitam yang memotong kotak merah merupakan garis irisan cross-section penampang geologi bawah permukaan (Sukardi, 1992).

\section{Karakteristik Air Lindi}

Pencucian sampah bisa terjadi salah satunya akibat dari air hujan. Hasil dari pencucian sampah ini menimbulkan pencemaran air tanah maupun air permukaan. Akibatnya, timbul kontaminasi sifat fisik maupun sifat kimia yang menyebabkan turunnya kualitas air. Air limbah hasil pencucian sampah ini yang disebut dengan air lindi (Trihadiningrum, 1995).

Air lindi yang merupakan hasil degradasi sampah tentunya mengandung unsur-unsur yang terlarut dan tersuspensi. Bila kondisi air lindi ini dibiarkan mengalir di permukaan tanah dan menyebar secara luas, maka akan menimbulkan dampak negatif bagi lingkungan. Sebagai contoh bila suatu TPA menimbun banyak sampah organik maka karakter air lindi yang dihasilkan akan mengandung zat organik tinggi disertai dengan bau yang busuk (Wulandari, 2015). Tabel 1 di bawah ini menjelaskan karakteristik yang dimiliki air lindi berkaitan dengan sifat kimiawi (Ali, 2011).

Tabel 1. Sifat Kimiawi Air Lindi (Ali, 2011)

\begin{tabular}{llc}
\hline \multicolumn{1}{c}{ Parameter } & \multicolumn{1}{c}{ Satuan } & Rentang \\
\hline $\mathrm{COD}$ & $\mathrm{mg} / \mathrm{liter}$ & $150-100.000$ \\
$\mathrm{BOD}_{5}$ & $\mathrm{mg} / \mathrm{liter}$ & $100-90.000$ \\
$\mathrm{pH}$ & - & $5,3-8,5$ \\
$\mathrm{NH}_{4}$ & $\mathrm{mg} / \mathrm{liter}$ & $1-1.500$ \\
$\mathrm{~N}-$ Organik & $\mathrm{mg} / \mathrm{liter}$ & $1-2.000$ \\
$\mathrm{~N}-\mathrm{Total}$ & $\mathrm{mg} /$ liter & $50-5.000$ \\
$\mathrm{NO}_{3}$ & $\mathrm{mg} /$ liter & $0,1-50$ \\
$\mathrm{NO}_{2}$ & $\mathrm{mg} /$ liter & $0-25$ \\
$\mathrm{PO}_{4}$ & $\mathrm{mg} /$ liter & $0,3-25$ \\
$\mathrm{Ca}$ & $\mathrm{mg} / \mathrm{liter}$ & $10-2.500$ \\
$\mathrm{Mg}$ & $\mathrm{mg} / \mathrm{liter}$ & $50-1.150$ \\
$\mathrm{Na}$ & $\mathrm{mg} /$ liter & $50-4.000$ \\
$\mathrm{~K}$ & $\mathrm{mg} /$ liter & $10-2.500$ \\
\hline
\end{tabular}




\section{Sifat Kelistrikan Batuan dan Mineral}

Sifat kelistrikan batuan akan ada ketika batuan tersebut dialiri arus listrik. Sifat kelistrikan pada batuan terletak pada kemampuan batuan untuk dapat menghantarkan dan menghambat arus listrik, atau biasa disebut dengan konduktivitas dan tahanan jenis. Kedua nilai tersebut konstan pada batuan dan mineral. Berdasarkan kemampuan menghantarkan arus listrik, sifat tahanan jenis batuan dibagi menjadi 3 bagian sebagai berikut :
a) Resistif
: resistivitas $>10^{7} \Omega \mathrm{m}$
b) Semikonduktif : resistivitas $1-10^{7} \Omega \mathrm{m}$
c) Konduktif : resistivitas $10^{-8}-1 \Omega \mathrm{m}$

Tabel 2. Tabel Resistivitas Batuan (Loke, 2015)

\begin{tabular}{lcc}
\hline \multicolumn{1}{c}{ Material } & $\begin{array}{c}\text { Resistivitas } \\
(\Omega \mathrm{m})\end{array}$ & $\begin{array}{c}\text { Konduktivitas } \\
\text { (Siemens.m) }\end{array}$ \\
\hline Granit & $5 \times 10^{3}-10^{6}$ & $10^{-6}-2 \times 10^{-4}$ \\
Basalt & $10^{3}-10^{6}$ & $10^{-6}-10^{-3}$ \\
Slate & $6 \times 10^{2}-4 \times 10^{7}$ & $2.5 \times 10^{-8}-1.7 \times 10^{-3}$ \\
Marble & $10^{2}-2.5 \times 10^{8}$ & $4 \times 10^{-9}-10^{-2}$ \\
Quartzite & $10^{2}-2 \times 10^{8}$ & $5 \times 10^{-9}-10^{-2}$ \\
\hline \multicolumn{3}{c}{ Batuan Sedimen } \\
\hline Batupasir & $8-4 \times 10^{3}$ & $2.5 \times 10^{-4}-0.125$ \\
Batulempung & $20-2 \times 10^{3}$ & $5 \times 10^{-4}-0.05$ \\
Batugamping & $50-4 \times 10^{2}$ & $2.5 \times 10^{-3}-0.02$ \\
\hline \multicolumn{3}{c}{ Tanah dan Air } \\
\hline Lempung & $1-100$ & $0.01-1$ \\
Aluvial & $10-800$ & $1.25 \times 10^{-3}-0.1$ \\
Air Tanah & $10-100$ & $0.01-0.1$ \\
Air Laut & 0.2 & 5 \\
\hline
\end{tabular}

Tabel 2 di atas menunjukkan nilai resistivitas dan konduktivitas yang dimiliki oleh batuan dan material. Setiap batuan dan material memiliki penyusun yang berbeda sehingga nilai sifat kelistrikan yang dimiliki pun berbeda. Nilai-nilai di atas memiliki rentang atas dan rentang bawah yang menunjukkan bahwa pada kondisi tertentu, nilai resistivitas atau konduktivitas yang dimiliki batuan tersebut bisa berbeda namun masih dalam rentang tersebut. Faktor yang menyebabkan muncul rentang tersebut bisa dari saturasi fluida dalam batuan ataupun campuran pada batuan tersebut.

\section{Metode Resistivitas 2D}

Metode Resistivitas 2D merupakan metode geofisika aktif yang memiliki konsep mengalirkan arus listrik ke bawah permukaan bumi dan mengukur beda potensial titik tertentu. Metode ini memanfaatkan sifat kelistrikan batuan perlapisan bumi untuk mengetahui variasi tahanan jenis bawah permukaan bumi baik secara horizontal maupun secara vertikal (Telford et.al, 1990).

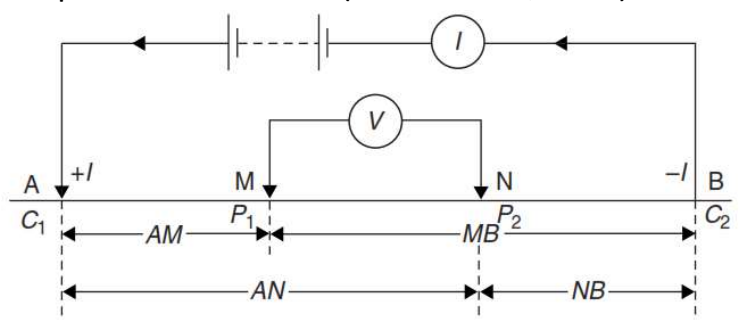

Gambar 2. Konsep Resistivitas 2D (Reynolds, 2011)

Gambar 2 menjelaskan tentang konsep dasar pengukuran metode Resistivitas 2D dengan menggunakan dua sumber arus ( $A B)$ dan dua pengukur tegangan (MN). Untuk dapat mengetahui nilai resistivitas semu dari satu pengukuran tersebut, digunakan rumus di bawah ini :

$$
\rho=R .2 \pi\left\{\left(\frac{1}{A M}-\frac{1}{M B}\right)-\left(\frac{1}{A N}-\frac{1}{N B}\right)\right\}^{-1}
$$

Bentuk konfigurasi yang digunakan dalam penelitian ini ialah Wenner-Schlumberger. Konfigurasi ini merupakan hasil perpaduan antara konfigurasi Wenner dengan Schlumberger. Posisi pemasangan elektroda konfigurasi WennerSchlumberger seperti pada di bawah ini.

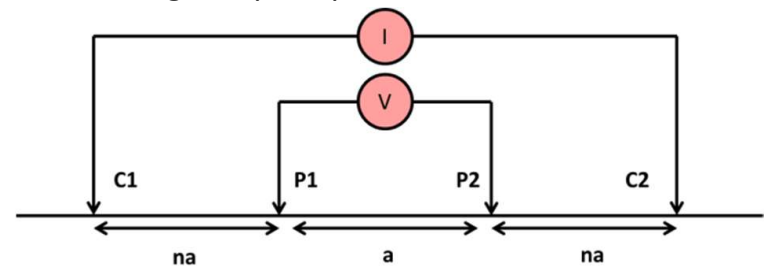

Gambar 3. Pemasangan Elektroda Konfigurasi WennerSchlumberger (Sumber : Penulis)

Nilai faktor geometri (K) dari konfigurasi pada Gambar 3 di atas ialah sebagai berikut :

$K=\pi n(n+1) a$

Keunggulan yang dimiliki konfigurasi WennerSchlumberger ialah mampu memetakan distribusi 
nilai resistivitas secara lateral dalam kehomogenan sekaligus mendeteksi adanya non-homogenitas lapisan secara vertikal. Penetrasi kedalaman lebih baik bila dibandingkan dengan konfigurasi Wenner (Reynolds, 2011).

\section{METODOLOGI PENELITIAN}

Lokasi penelitian lapangan berada di TPA Ngipik Kabupaten Gresik dengan koordinat $7^{\circ}$ 9'10.60"S dan 112³7'55.41"E (Gambar 4).

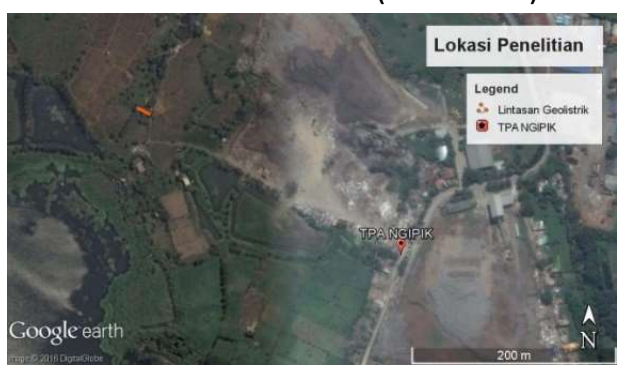

Gambar 4. Lokasi Penelitian

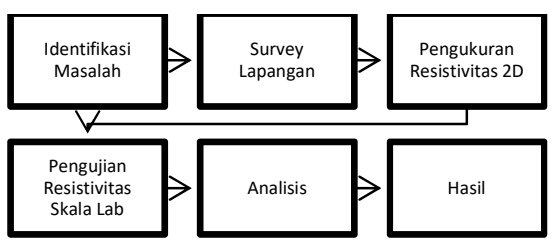

Gambar 5. Diagram Alir Penelitian

Dalam penelitian ini digunakan beberapa data meliputi data primer dan data sekunder. Data primer diantaranya pengukuran Resistivitas 2D di mana lokasi pengukuran berada di bagian Barat TPA Ngipik (Gambar 4 dengan tanda garis oranye) dan uji resistivitas skala laboratorium. Pengukuran Resistivitas 2D menggunakan 32 elektroda dengan spasi 0.5 meter dan total panjang lintasan 15.5 meter. Sedangkan data sekunder yang digunakan yakni data hasil pemboran. Pengukuran Resistivitas 2D dilakukan sebanyak 2 kali pada dua musim yang berbeda yakni musim kemarau (27 Agustus 2016) dan penghujan (22 Januari 2017).

Peralatan yang digunakan dalam pengukuran lapangan diantaranya :
o 1 set Resistivitimeter
○ 1 set Meteran
- 1 set Palu
- 32 buah Elektroda
○ 4 roll Kabel

\section{HASIL DAN PEMBAHASAN}

\section{Hasil Uji Resistivitas Skala Lab}

Uji resistivitas skala laboratorium ini dilakukan untuk mengetahui respon resistivitas sampel tanah lokasi penelitian terhadap perbedaan fluida yang tersaturasi. Hasil dari pengujian ini digunakan sebagai dasar penentuan zona sebaran air lindi pada hasil penampang Resistivitas 2D. Dari pengujian yang sudah dilakukan, dapat diketahui bahwa dari dua sampel uji yang telah diukur, keduanya mengalami penurunan nilai resistivitas pada setiap perlakuan penambahan fluida yang diberikan.

Gambar 6 menunjukkan perubahan resistivitas terhadap kandungan aquades dan Gambar 7 perubahan resistivitas terhadap kandungan air lindi. Dari grafik tersebut diambil persamaan regresi power untuk mengetahui nilai resistivitas pada setiap kedalaman bor.

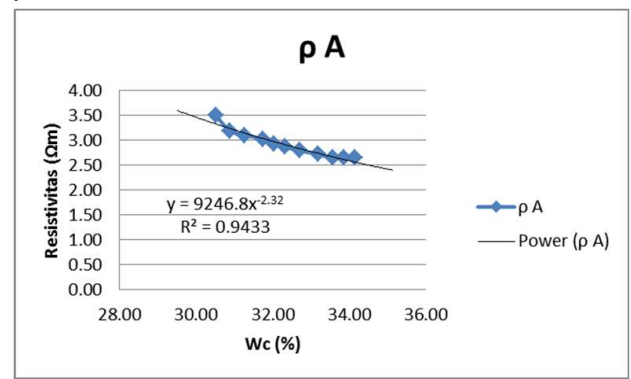

Gambar 6. Grafik perubahan resistivitas terhadap kandungan aquades

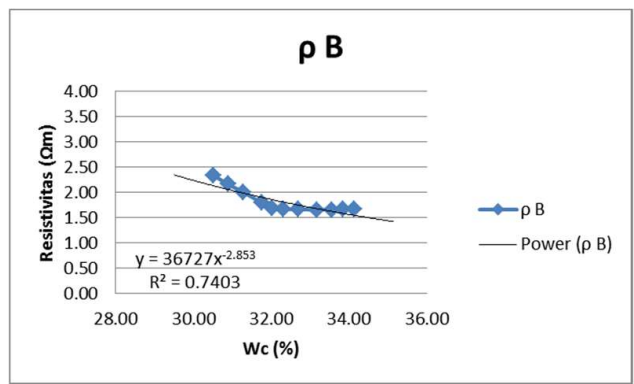

Gambar 7. Grafik perubahan resistivitas terhadap kandungan air lindi

Pada setiap kedalaman dua meter titik bor, telah dihitung kandungan fluidanya. Berikut nilai resistivitas pada kedalaman titik bor tertentu. 
Tabel 3. Nilai Resistivitas terhadap Kandungan Fluida Bor

\begin{tabular}{cccc}
\hline $\begin{array}{c}\text { Kedalaman } \\
(\mathrm{m})\end{array}$ & $\begin{array}{c}\text { Wc } \\
(\%)\end{array}$ & $\begin{array}{c}\rho \mathrm{A}(\Omega \mathrm{m}) \\
\text { (aquades) }\end{array}$ & $\begin{array}{c}\rho \mathrm{B}(\Omega \mathrm{m}) \\
\text { (air lindi) }\end{array}$ \\
\hline 2 & 51.46 & 0.99 & 0.48 \\
4 & 48.52 & 1.13 & 0.57 \\
6 & 57.11 & 0.78 & 0.36 \\
8 & 30.71 & 3.28 & 2.10 \\
10 & 30.63 & 3.30 & 2.11 \\
12 & 29.74 & 3.53 & 2.30 \\
14 & 30.96 & 3.22 & 2.05 \\
\hline
\end{tabular}

Dari hasil nilai resistivitas di Tabel 3, dapat diketahui bahwa ada perbedaan resistivitas antara sampel dengan saturasi aquades dan air lindi. Rentang resistivitas sampel dengan saturasi aquades yakni $0.78-3.53 \Omega \mathrm{m}$ dan dengan saturasi air lindi yakni $0.36-2.30 \Omega \mathrm{m}$. Dari perbandingan kedua hasil tersebut dapat dinyatakan bahwa pengaruh air lindi lebih besar terhadap nilai resistivitas menjadi semakin kecil.

\section{Penampang Hasil Inversi}

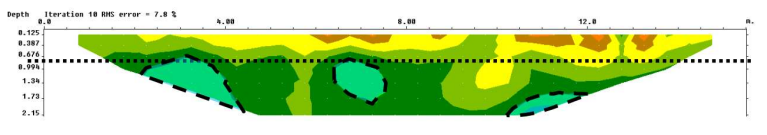

(a)

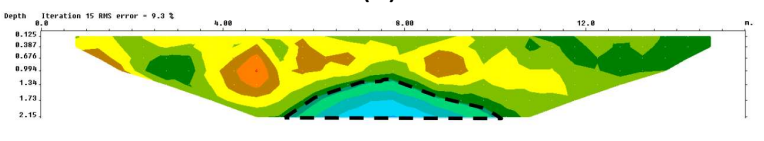

(b)

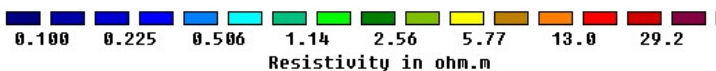

Gambar 8. Penampang Hasil Inversi Resistivitas 2D, (a) Musim Kemarau, (b) Musim Penghujan

Lintasan pengukuran Resistivitas 2D ini berada di sebelah Barat TPA Ngipik dengan jarak kurang lebih 100 meter dari tempat pembuangan sampah baru. Lokasi pengukuran dekat dengan titik pemboran sehingga data hasil pemboran juga bisa dipakai sebagai data penunjang analisis hasil penampang. Kondisi lapangan merupakan areal persawahan dengan permukaan tanah yang kering retak-retak saat musim kemarau dan agak gembur pada musim penghujan.
Hasil penampang hasil inversi pada Gambar 8 memiliki nilai rentang resistivitas $0.5-13 \Omega \mathrm{m}$. Pada

Tabel 2 dapat diketahui bahwa Loke (2015) menyatakan nilai resistivitas lempung dalam batas bawah bisa mencapai $1 \Omega \mathrm{m}$. Sehingga secara garis besar diinterpretasikan nilai resistivitas tersebut merupakan lempung. Dan hasil ini juga sesuai dengan analisa hasil pemboran yang menyebutkan bahwa hingga kedalaman 30 meter, tanah yang mendominasi ialah lempung. Yang membedakan nilai resistivitas pada penampang hasil inversi ialah saturasi air yang terdapat di dalam lapisan

Penampang hasil inversi musim kemarau (Gambar 8. a) menunjukkan bahwa sebaran nilai resistivitas memiliki nilai yang tidak jauh berbeda secara signifikan. Muka air tanah pada penampang dilambangkan dengan garis panjang putus-putus. Muka air tanah saat pengukuran berlangsung yakni sedalam $75 \mathrm{~cm}$. Bila merujuk pada analisa hasil pemboran, kandungan air pada kedalaman 1.5 - 2 meter sebesar $51.46 \%$, maka nilai resistivitas < $2.56 \Omega \mathrm{m}$ menunjukkan tanah lempung yang tersaturasi oleh air. Sedangkan pada lempung di atas muka air tanah memiliki resistivitas $>5.77 \Omega m$ atau menunjukkan lempung yang relatif kering.

Terdapat anomali resistivitas rendah yang ditunjukkan dengan blok garis putus-putus dengan nilai resistivitas $<1.5 \Omega \mathrm{m}$. Anomali tersebut diinterpretasikan sebagai lempung yang terdapat akumulasi air lindi. sedangkan nilai $<2.56 \Omega \mathrm{m}$ diinterpretasikan sebagai lempung yang mendapatkan pengaruh dari air lindi dan air biasa. Sehingga nilai resistivitas yang terukur tidak terlalu kecil seperti yang terukur ketika akumulasi lindi.

Pada penampang hasil inversi musim penghujan (Gambar 8. b), terlihat bahwa sebaran nilai resistivitas lebih banyak $>5.77 \Omega \mathrm{m}$. Ada anomali dengan nilai resistivitas rendah sebesar $0.15-0.75 \Omega \mathrm{m}$ pada kedalaman 2 meter, di tengah lintasan pengukuran. Titik tersebut diinterpretasikan sebagai lempung yang terakumulasi oleh air lindi. Sedangkan zona dengan nilai resistivitas > $2.56 \Omega \mathrm{m}$ diinterpretasikan sebagai lempung yang saturasinya lebih besar dipengaruhi oleh air hujan. Sehingga yang semula pada musim kemarau memiliki nilai resistivitas < 
$2.56 \Omega \mathrm{m}$ ketika musim penghujan naik menjadi > $2.56 \Omega \mathrm{m}$. Hal ini selaras dengan hasil uji resistivitas skala lab yang menunjukkan bahwa nilai resistivitas lempung yang dipengaruhi oleh air biasa lebih tinggi bila dibandingkan dengan lempung yang tersaturasi oleh air lindi.

\section{PENUTUP}

\section{Simpulan}

Dari hasil penelitian yang telah dilakukan dapat diambil kesimpulan sebagai berikut :

1. Nilai resistivitas hasil inversi menunjukkan litologi yang sama dengan data hasil pemboran yakni litologi lempung dengan rentang resistivitas $0.1-43.78 \Omega \mathrm{m}$.

2. Hasil uji resistivitas skala lab menunjukkan bahwa nilai resistivitas lempung dengan saturasi air lindi lebih kecil dibandingkan lempung dengan saturasi air aquades.

3. Pada lintasan pengukuran resistivitas $2 D$ sudah teridentifikasi sebaran air lindi dengan nilai resistivitas $0.1-1.5 \Omega \mathrm{m}$.

4. Kedalaman sebaran air lindi yakni lebih dari sama dengan 1 meter.

\section{Saran}

Saran yang penulis diberikan untuk penelitian selanjutnya ialah :

- Perlunya dilakukan pengujian air secara fisis dan kimiawi untuk mengetahui kandungan air di titik penelitian.

- Pengukuran Resistivitas 2D bisa dilakukan dengan bentangan yang panjang namun dengan spasi yang rapat untuk mendapatkan target yang lebih dalam.

- Uji resistivitas skala laboratorium bisa dilakukan dengan metode pengujian lain yang lebih akurat.

\section{UCAPAN TERIMA KASIH}

Penelitian ini telah didanai oleh dana Hibah penelitian Pendidikan Magister menuju Doktor untuk Sarjana Unggul (PMDSU).

\section{DAFTAR PUSTAKA}

Ali, M. (2011). Monograf Rembesan Air Lindi (Leachate). Surabaya, Jawa Timur: UPN Veteran Jawa Timur.

BAPPEDA Kabupaten Gresik. (2016). RPJMD Kabupaten Gresik Tahun 2016-2021. Gresik, Jawa Timur: BAPPEDA Kabupaten Gresik.

Loke, M. (2015). Tutorial : 2-D and 3-D Electrical Imaging Surveys. Malaysia: M.H. Loke.

Lopes, D. D., Silva, S. M., Fernandes, F., Texeira, R. S., Celligoi, A., \& Antonia, L. H. (2012). Geophysical Technique and Groundwater Monitoring to Detect Leachare Contamination in the Surrounding Area of a Landfill - Londrina (PRBrazil). Journal of Environtmental Management, 113, 481-487.

Parlainggonan, R. H. (2011). Studi Sebaran Air Limbah Sampah Bagian Utara TPA Bantar Gebang dengan Metoda Resistivity WennerSchlumberger. Skripsi, Universitas Indonesia, Departemen Fisika, Jakarta.

Putra, I. K. (2012). Identifikasi Arah Rembesan dan Letak Akumulasi Lindi dengan Metode Geolistrik Resistivitas Konfigurasi Wenner-Schlumberger di TPA Temesi Kabupaten Gianyar. Thesis, Universitas Udayana, Program Pascasarjana, Bali.

Reynolds, J. M. (2011). An Introduction to Applied and Environmental Geophysics. Chichester: WileyBlackwell.

Sukardi. (1992). Peta Geologi Lembar Surabaya \& Sapulu, Jawa. Bandung: Pusat Penelitian dan Pengembangan Geologi.

Telford, W. M., Geldart, L. P., \& Sheriff, R. (1990). Applied Geophysics (2nd ed.). New York: Cambridge University Press.

Trihadiningrum, Y. (1995). Mikrobiologi Lingkungan. Surabaya: Teknik Lingkungan-ITS.

Widyatmoko, H., \& Moerdjoko, S. (2002). Menghindari, Mengolah dan Menyingkirkan Sampah. Jakarta: Abdi Tandur.

Wulandari, R. S. (2015). Identifikasi Pertambahan Persebaran Limbah Tempat Pembuangan Akhir (TPA) Jatibarang Menggunakan Metode Geolistrik. Skripsi, Universitas Negeri Semarang, Jurusan Fisika, Semarang. 